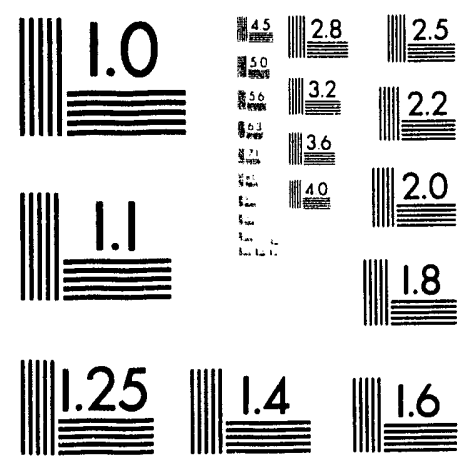



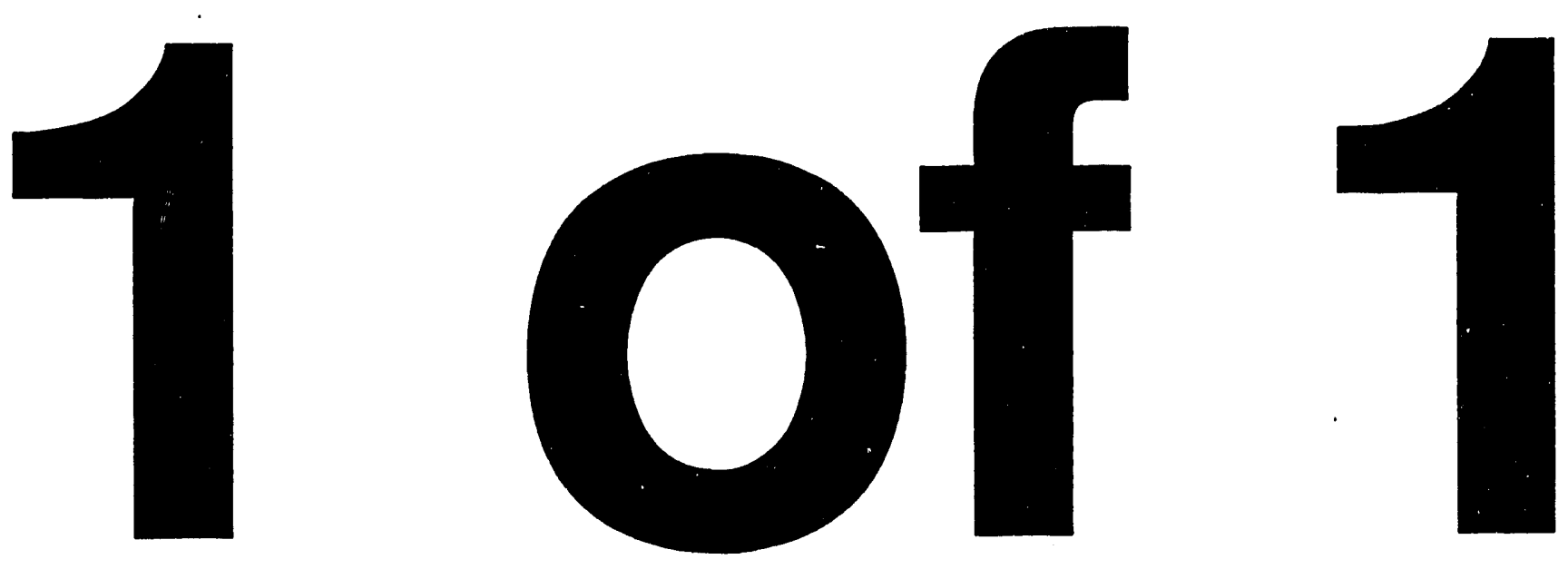


\title{
The Tokamak Fusion Test Reactor Tritium Systems Test Contractor Operational Readiness Review
}

\author{
C.A. Gentile, J. Levine, M. Norris, F. Rehill, and C. Such \\ Princeton Plasma Physics Laboratory \\ US Route 1-North, Box 451, Princeton, New Jersey 08543
}

\section{ABSTRACT}

In preparation for D-T operations at TFTR, the TFTR project has successfully completed the C-ORR process which has led to the introduction of 200 curies of tritium to the site. Preparations for the C-ORR began approximately 2 years ago. During July 1992 a one-week Site Assistance Review was conducted by the C-ORR Chairman, and C-ORR Team consisting of 12 persons, all of whom were outside experts, many of whom were from other facilities within the DOE complex. During the July 1992 Site Assistance Review 201 findings were documented which fell into one of throe categories. All of the 109 category one findings which were generated were required to be resolved prior to the introduction of tritium to the TFTR site. On April 5, 1993, the TFTR Tritium System Test C-ORR commenced. The results of the CORR as documented in the final report by the C-ORR Chairman was that category 1 findings were resolved, and it was the recommendation of the C-ORR Team to the PPPL ES\&H Board that TFTR initiate the Tritium Systems Test. DOE (Chicago Operations, Princeton Area Office) concurred with the C-ORR final report, and on April 29. 1993, at 12:15 pm tritium was introduced to the TFTR site.

"Work supported by US DOE Contract No. DE-ACO2-76CHO3073.

\section{INTRODUCTION}

During the summer of 1991, the TFTR project, realizing the regulatory obstacles which lay ahead in successfully performing the required Operational Readiness Review (ORR) and bringing tritium to PPPL, formed an (ES\&H) compliance branch. The project's ES\&H branch reported directly to the TFTR Project Office, with the primary objective of identifying ORR tasks, including DOE orders which were germane to bringing tritium to the PPPL site. This work was performed in consultation with the independent PPPL ES\&H Division.

The first task the newly formed ES\&H branch performed was to develop a Regulatory Compliance Plan (RCP). The RCP provided a "road map" which documented and tracked applicable DOE orders, regulatory standards, and TFTR's level of compliance with such regulations. The RCP was mutually agreed to by PPPL senior managers and DOE officials regulating the management of the TFTR project.
The RCP identified dozens of tasks which would be required to bring TFIR to a successful ORR and to D-T operations, once such tasks were brought to closure.

\section{FSAR}

The TFIR Final Safety Analysis Report (FSAR) was one of many tasks reflected in the RCP which required closure prior to proceeding with D-T. The FSAR was approved by DOE in 1982, was revised in 1988, and again in the 1990-1991 time frame to reflect the condition of the TFTR facility. In September 1991, the Department of Energy formed the Independent Review'Group (IRG). The IRG was formed for the purpose of reviewing the TFTR FSAR and to make a recommendation to the Director of the DOE Office of Fusion Energy (OFE) on the results of the review. It was planned that the IRG would conduct its review from September 1991 to December 1991, and generate a report to be submitted to OFE in late December 1991. The IRG review consisted of site visits, review of source documents, and reviewing the FSAR directly. During this time period, the IRG consisted of personnel from within DOE and INEL. During the four month review period, the TFIR project supplied the IRG with several thousand pages of source documents including piping and instrumentation diagrams (P\&IDs), control wire diagrams (CWDs), seismic reponts, meteorological studies of the TFTR site, hydrological studies of the TFTR site. demographic studies of the area, etc. In December 1991, the IRG requested a meeting with PPPL in Washington D.C. to discuss the information previousiy received, the need for additional information, and comments which members of the IRG had documented during their review. The IRG, in conjunction with DOE-Chicago, and OFE had submitted > 400 comments (including requests for additional information) on the FSAR. The IRG contracted - additional experts in the area of seismic qualification, industrial hygiene, and fire protection. The TFTR project responded by allocating additional resources to the FSAR, funding TFIR project engineers and consultants worting on the project. The TFTR FSAR was ultimately reviewed by members of the IRG, DOE-Chicago (CH), DOE-OFE, INEL, DOE Office of Nuclear Safety (ONS) and DOE Environment Safety and Health (EH). A total of thirty-one outside experts reviewed and commented on the FSAR. In September 1992, the IRG generated a Safety Evaluation Report (SER) which endorsed the FSAR for the TFTR Tritium Systems Test ( 1000 curies tritium). Additional information was requested prior to full D-T operations at TFTR would be approved.

The IRG maintained its review function for several 
months after the issuance of the SER. In November 1992. DOE-Chicago was delegated as the approving authority for the FSAR by the Director of the Offlce of Energy Research. After a review of the SER, and consultation with members of the IRG, DOE-Chicago approved the FSAR for D-T operations in April, 1993. A persistent challenge for both PPPL and DOE in the review and approval of the FSAR was the implementation of a "graded approach". TFTR is a category 3 , low hazard facility with no nuclear safety class systems, and as such required a level of review commensurate with the associated hazard. The concept of a "graded approach" is subjective, with varying interpretation on how it is implemented. Since April 1993, several minor revisions to the FSAR have been made via the Unreviewed Safety Question Determination (USQD) Process. DOE Order 5480.21 Unreviewed Safety Questions requires that changes to the facility or Safety Analysis which could have an impact on safety (and were not previously reviewed) be technically reviewed for safety concerns. A USQD check list was developed to screen such revisions. To date over 100 USQDs have been performed for TFTR, with approximately two dozen USQDs revisions to the FSAR. The USQD process provides a vehicle by which FSAR revisions having no impact on safety can be implemented in a timely fashion, and not require approval outside of the laboratory.

\section{TSR}

A Technical Safety Requirements (TSR) document was developed in compliance with DOE Order 5480.22, concurrent with the IRG review of the FSAR. The IRG took part in the TFTR TSR development and review process. DOE Order 5480.22 brought many "firsts" with it. TFTR was the first Energy Research (ER) facility to be required to develop a TSR document. The TSR document generated much debate over the course of several months. Prior to this time TSR documents were requirements more closely associated with fission reactors. Fusion reactors do not easily fit into the requirements of TSR documents. A TFTR TSR document consisting of administrative control requirements, (consistent with its characterization as a "Low Hazard Facility"), was finally developed, and submitted to the DOE. Approval for the TSR document was received by DOE in April 1993. In addition to submitting a TSR document, TFTR also developed an operations procedure which established the operating parameters for tritium operations. The TSR operation document details the requirements necessary for maintaining a specific configuration and defines various operations of tritium movement throughout the TFTR facility.

\section{AUTHORIZATION BASIS}

An authorization basis defining a "safety envelope" was developed for TFTR. The authorization basis are those aspects of the facility design basis and operational requirements relied upon by DOE to authorize operation. The TFTR authorization basis includes the environmental assessment (EA), FSAR (including USQD revisions), the TSR (including implementing operational documents) and the SER. Revisions to the authorization basis which would change the parameters of the safety envelope require DOE approval prior to implementation.

\section{ORR TEAM SITE VISIT}

During the last week of July 1992, the Contractor Operational Readiness Review (C-ORR) chairman along with a team of 12 persons, visited the TFTR site to become acquainted with TFTR, and to conduct a Site Assistance Review. The purpose of the Site Assistance Review was to review the FSAR, TSR, USQD check list, TFTR tritium operation procedures, fire protection procedures, tritium accountability, conduct of operations, etc., and to identify to PPPL what areas would require additional attention.

During this review, 201 findings were generated. These findings were divided into three categories. 109 findings were categorized as Category One findings, requiring resolution prior to bringing tritium or -site in quantities < 1000 curies, 64 were Category Two findings requiring resolution prior to bringing 50,000 curies of tritium on-site, and 28 were categorized as Category Three findings falling in the area of suggested practices which should be considered prior to D-T operations.

During the winter of 1992 much of the TFTR staff weie actively involved in bringing issues associated with the site assistance review to closure.

On April 5, 1993, the TFTR Tritium System Test (TST) ORR commenced. The C-ORR team consisted mainly of the majority of the same members of the 1992 review team. During the 2 week review, the C-ORR team reviewed all previous findings, conducted an emergency drill, reviewed tritium operating procedures and re-reviewed previously submitted documents (i.e. FSAR, TSR, USQD procedures, etc.).

At the conclusion of the C-ORR (TST), it was the unanimous consensus of the ORR team that Category One findings were successfully resolved, and that TFTR should proceed with the TST. The C-ORR chairman - documented the results of the C-ORR and recommended to the PPPL ES\&H Board that TFTR proceed with bringing $<1000$ curies of tritium to TFTR to conduct the Tritium Systems Test. DOE concurred with the recommendations of the C-ORR chairman and approved the delivery of tritium to TFTR.

On April 29, 1993 at 12:15 pm, 200 curies of tritium from the Tritium Systems Test Assembly (TSTA) in Los Alamos, New Mexico arrived at the TFTR. 


\section{DISCLAIMER}

This report was prepared as an account of work sponsored by an agency of the United States Government. Neither the United States Government nor any agency thereof, nor any of their employees, makes any warranty, express or implied, or assumes any legal liability or responsibility for the accuracy, completeness, or usefulness of any information, apparatus, product, or process disclosed, or represents that its use would not infringe privately owned rights. Reference herein to any specific commercial product, process, or service by trade name, trademark, manufacturer, or otherwise does not necessarily constitute or imply its endorsement, recommendation, or favoring by the United States Government or any agency thereof. The views and opinions of authors expressed herein do not necessarily state or reflect those of the United States Government or any agenc', thereof. 

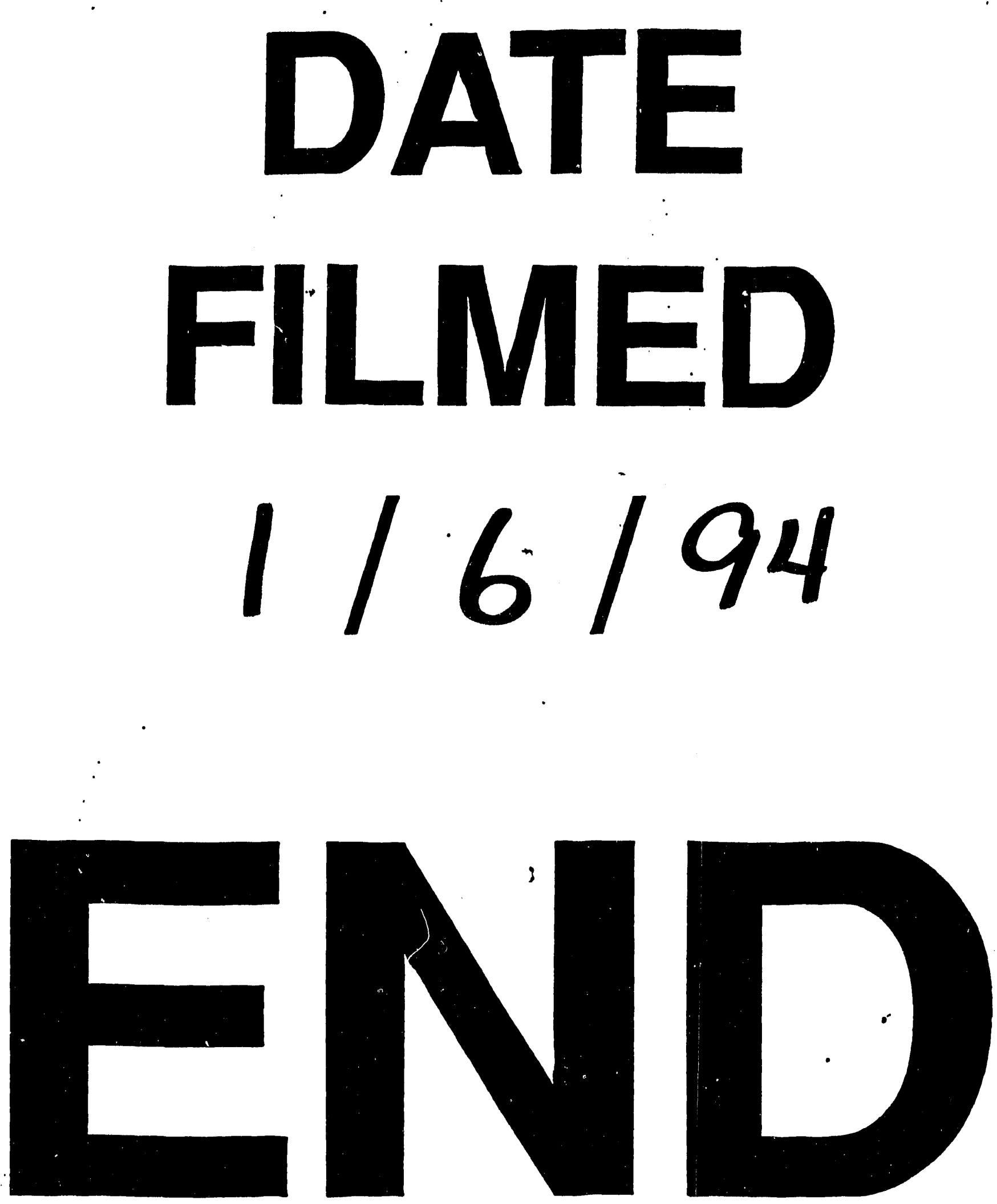
